\title{
Autonomous Controller for Flexible Operation of Heat Pumps in Low-Voltage Distribution Network
}

\author{
Rakesh Sinha *(D), Birgitte Bak-Jensen $(\mathbb{D}$ and Jayakrishnan Radhakrishna Pillai \\ Department of Energy Technology, Aalborg University, 9220 Aalborg, Denmark; bbj@et.aau.dk (B.B.-J.); \\ jrp@et.aau.dk (J.R.P.) \\ * Correspondence: ras@et.aau.dk; Tel.: +45-9356-2203
}

Received: 20 March 2019; Accepted: 15 April 2019; Published: 18 April 2019

\begin{abstract}
This paper aims to unleash the potential of a heat pump (HP) and its storage system, as a flexible consumer load, in the low-voltage (LV) distribution network by introducing an autonomous controller. Steady-state analysis using DigSILENT Power Factory, a power system analysis tool, is performed to verify the proposed hypothesis. The proposed controller manages to operate the individual HP and storage within the recommended operating limits of grid voltage, by sharing flexibility within the specific network. It has the capability of sensing local key control parameters for scheduling, re-scheduling, and decision-making on the operation of individual HPs. It also takes the thermal energy comfort of individual consumers into consideration. Measurement of local parameters such as grid voltage, supply temperature and level of cold water in the storage tank defines the priority for operation of HPs based on operating delays for turning it on and off. This enhances the sharing of flexibility for proper coordination, control, and management of HP systems in LV distribution networks with mutual technical benefits. From the results, the application of the proposed controller is found to be effective to manage grid congestions and local voltage regulation, satisfying the thermal energy requirements of the customer.
\end{abstract}

Keywords: autonomous controller; multi-energy system; flexible load; power-to-heat; heat pumps; LV distribution network

\section{Introduction}

Hot water is used for space heating and domestic applications. With the concept of power-to-heat (P2H) in smart energy systems to incorporate $100 \%$ renewables, heat pumps (HPs) are expected to play an important role for thermal heating and cooling due to their high output-to-input ratio. HPs are also considered to be a key technology supporting the European strategy for thermal systems decarbonization [1]. Furthermore, low-temperature district heating, to reduce transmission loss of thermal energy, requires boosting of hot water for end users [2,3]. The combination of distributed HPs and district heating systems, with high penetration of renewables in power system networks, have a significant potential in low-temperature district heating systems [4]. In [5] the authors investigate the life-cycle cost for use of district heating or distributed HPs and find it depends on the energy system economy. Use of electric boilers (EBs) has been unfavorable due to high electricity prices and taxes in the Swedish system whereas, HPs are providing high flexibility in power-to-heat supply [6] and a high coefficient of performance (COP) when compared to EBs. Individual HPs seem to be the best alternative to district heating to replace individual boilers (based on oil, natural gas or biomass) in rural or suburban areas, where heat densities are lower [7]. This indicates the installation of many HPs in the near future as well as a significant increment in residential electricity demand. Control of HPs plays an immense role in the flexible operation for demand response. HPs can be controlled based on a simple start and stop operation. A wide variety of HPs is available on the market 
with on/off regulation supported by a hot water storage tank. Ref. [8] uses on/off control of HP coupled in a single house located in Italy to investigate the dynamics of model based on the seasonal COP. In [9], on/off control method of HP is compared with other common control technique such as Constant hysteresis, Floating hysteresis, and Degree-Minute. Although there are several possibilities to control the HP, the problem here is simplified with just on and off in order to demonstrate the flexibility in the operation of HPs to fulfill thermal demand and support and avoid under-voltage situations in the electrical grid.

This paper is focused on the concept of on/off control, to achieve flexibility from many HPs associated with individual residences (164 houses) in a low-voltage (LV) $(0.4 \mathrm{kV})$ electrical distribution network supplied from a $630 \mathrm{kVA}$ transformer. Individual controllers, linked with the respective HP, functions independently to avoid under-voltage situations in the electrical grid as well as to fulfill the thermal demands simultaneously. The decision-making capability for the controllers is enhanced with delay functions to turn on/off the HPs based on their terminal voltage at the point of coupling as well as temperature and level of hot water in the storage tanks.

Heat storage is essential for the flexible operation of a heating system. The concept of using thermal inertia of a heating grid as energy storage is presented in [10], without addressing the issues related to leakage of thermal fluid and significant heat loss to the surrounding from the transmission pipes. The effective size of the storage tank plays an important role in controlling the grid load by creating enough buffer to supply thermal demand without operation of HPs, during the period of the high electrical load. On the other hand, low-cost electricity during periods of high renewable electricity production from wind and solar can be used for heat generation and storage, increasing the economic efficiency and sustainability of multi-energy systems. Several works of literature have investigated that without proper management of heat generating units in power-to-heat $(\mathrm{P} 2 \mathrm{H})$, problems associated with transformer loadings, line loadings, and voltage drops can be prominent in some of the existing LV distribution networks [11-13]. In [11] hysteresis control of the heating unit based on grid voltage, the temperature of hot water and accumulation of cold water in the storage tank is investigated for flexible operation of thermal units. This technique of control has possibilities of storage tank being fully discharged after the event of low terminal voltage for the long duration operating restriction. In [12], the proposed controller can operate the thermal unit despite low voltage during an event when energy stored in the storage tank is critically low which can stress the grid. Ref. [13] examines the starting current, voltage variation and, active and reactive power impact of single-phase loading of the network suggesting necessity of demand response.

Mixed integer programming based on the daily scheduling of individual heating systems, based on power fluctuation, are derived from their set of optimal schedules using the coordinated algorithm in [14]. This requires frequent and proper communication channel between heating systems. Price-based decentralized load coordination with proper communication is presented in [15]. Ref. [16] studied on flexibility by shifting operation of HPs to optimise operational costs. Ref. [17] examined flexibility in the operating times of HPs against the resulting impact on the end user's comfort. Ref. [18] investigated on the flexibility of distributed HPs for trading on the intra-day market. None of them considered the performance and violation of electric grid parameters. The centralized control algorithm is designed in [19] to exploit flexibility considering end-user thermal comfort which requires proper communication channel. A combination of both centralized and decentralized framework is proposed based on forecasting and power-voltage droop concept respectively in [20], considering fair use of flexibilities from customers. Agent-based control system with complex computation is presented in [21], where it is difficult to predict overall system behavior.

The anticipation of a real-time autonomous controller for coordination in the management of HPs, to overcome these issues, is proposed in this paper by distributing the use of HPs consumption over time. The proposed controller senses local information relatively delay free, enhancing a quick decision-making process compared to a centralized control system [22]. It has the capability of sensing, scheduling, re-scheduling, and decision-making that can act flexibly and autonomously in the specific 
environment to meet its design objectives. The main advantage of this proposed control system is that there is no need for extra investment in communication infrastructure for the management of flexible loads. This article focuses on an on/off control strategy (to simplify the problem) to effectively introduce high shares of individual HPs, in low-voltage (LV) residential networks, as a sustainable solution towards $\mathrm{P} 2 \mathrm{H}$ systems. The effect on the control strategy based on the selection of different initial conditions and operating power factor of HPs are well illustrated through various case studies.

This paper is organized as follows. A short overview of the working principle of HP and its modeling with respect to power-to-heat $(\mathrm{P} 2 \mathrm{H})$ is presented in Section 2 along with the concept of a model of a simple stratified hot water storage tank. Section 3 presents an overview of the LV residential network and the grid voltage situation with only residential load (without HP connected). The details of the logical concept of the proposed local controller and its significance for the flexible operation of HPs is discussed in Section 4. Simulation environment with various case studies, based on initial conditions, are discussed in Section 5, followed by result and discussion in Section 6. Finally, the outcome of the research is concluded in Section 7.

\section{Heat Pump and Storage}

A HP basically consists of three major components: evaporator, compressor, and condenser. Liquid refrigerant is exposed to the source, through the HP's evaporator coil, at a low temperature and pressure. As this refrigerant picks up energy from the source, it changes its state from liquid to gas within the evaporator coil. Then the gaseous fluid is passed through the compressor pump where it is pressurized. As a consequence, the temperature of this pressurized refrigerant increases. This heated refrigerant is passed through the condenser (a coil wrapped around the tank, or a pumped heat exchanger to feed a separate water storage tank) to discharge its heat energy. After passing through the condenser, the heated refrigerant cools and condenses back into liquid form. It is then passed through an expansion valve, where its pressure is reduced, and the cycle starts over. Thus, HP does not produce hot water instantaneously when turned on. It takes around 10-15 min to achieve a steady state condition [23]. Figure 1 shows the step response of the HP during turn-on and turn-off. The HP is turned on at time $T_{1}$, but it only starts delivering hot water after time $T_{2}$.

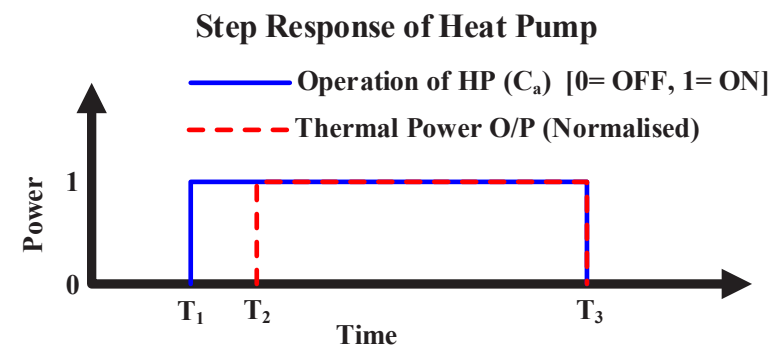

Figure 1. Step response of heat pump during turn-on and turn-off.

HPs can operate down to the voltage level of 0.7 pu or below. Different types of HPs are available in the market. They can be generally divided into two categories: inverter-based and non-inverter-based units. Non-inverter-based directly connected HPs exhibits low harmonic content and high inrush current compared to inverter-based [24]. The power factor of most inverter-based HPs, operating within the voltage range of $0.9-1 \mathrm{pu}$, is between 1 to 0.95 leading, whereas few HPs operates within 1 to 0.95 lagging [25]. Non-inverter-based HP draw inrush current nearly 5 times its nominal value, whereas, inverter driven HP units draw inrush current of the same order of magnitude as per their nominal rating. However, in some inverter drive models of HP, there exist spikes due to the charging of inverter's Direct Current (DC) bus capacitors [25].

The thermal power delivered by the HP is given by Equation (1). Here, $P_{H P}$ is the electrical power rating of the HP (W), $\dot{Q}_{\text {Heat }}$ is the heat delivered by HP (W). The step response of HP is modeled as shown in Figure 1 with a time delay of $10 \mathrm{~min}$. The reactive power delivered or consumed by the HP 
based on leading or lagging pf respectively is given by Equation (2). The relevant parameters of HP such as flow temperature of hot water $T_{\text {hot }}=70^{\circ} \mathrm{C}$ and $\mathrm{COP}=3$ during cold winter season (constant value of COP is selected for simplicity) are selected based on the manufacturer's data-sheet.

$$
\begin{array}{cc}
\dot{Q}_{\text {Heat }}=C O P \times P_{H P} & {[W]} \\
Q_{H P}=\mp P_{H P} \times \tan \theta & {[V A R]}
\end{array}
$$

The simplified hot water storage tank, based on a single thermocline layer of varying height as shown in Figure 2, separating the storage tank into two layers (upper hot and bottom cold) is modeled as presented in $[11,26]$ with appropriate assumptions and theoretical validation considering charging and discharging of storages tank. It is assumed that

- The heating element (condenser coil of HP) is attached to the bottom cold layer of the tank.

- There is an exchange of heat between the condenser, at the bottom of the storage tank, and the water inside the storage during operation of the HP.

- The thermocline inside the tank is horizontal and independent of radial distance from the side wall of the storage tank.

- The thermocline remains only when the HP is turned off and there is no exchange of heat between the condenser and the storage tank

- When HP is turned on and there is heat transfer to the storage tank, the thermal stratification is destroyed by water turbulence and there is mixing of hot and cold liquid creating uniform temperature inside the storage tank [27].

The stratified layer provides crucial information on the energy status of the storage tank based on the level of cold water filled inside the tank and temperature of the hot water inside the tank. These parameters are vital for the control logic to flexibly operate HPs as distributed local units and this is discussed in Section 4.

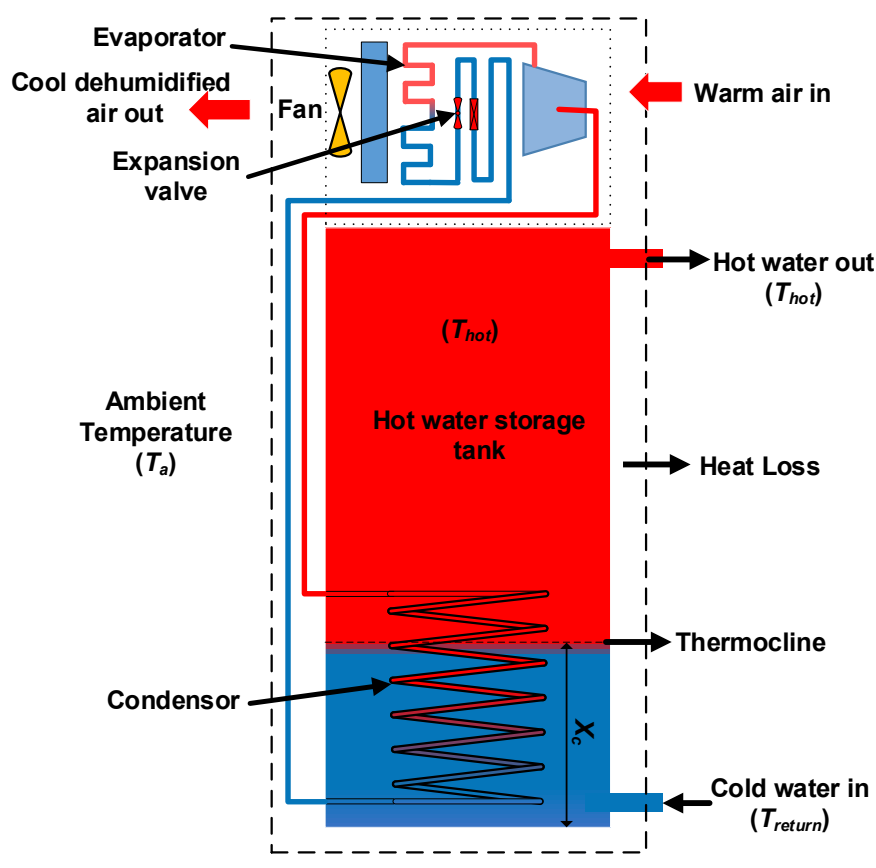

Figure 2. Heat Pump and Storage. 
The temperature of hot water $\left(T_{h o t}\right)$ is calculated as per Equation (3) during the presence of the thermocline layer.

$$
\frac{d T_{h o t}}{d t}=\frac{-1}{C_{b}\left(1-X_{c}\right)}\left[U A_{s}\left(1-X_{c}\right)\left(T_{h o t}-T_{a}\right)+U A_{t}\left(T_{h o t}-T_{a}\right)\right]
$$

Here,

$A_{s}$ and $A_{t}=$ surface area of side wall and top roof of the storage tank respectively $\left[\mathrm{m}^{2}\right]$ and $A=A_{s}+A_{t}$ $U=$ overall heat transfer coefficient $\left[2.5 \mathrm{~W} / \mathrm{m}^{2} \mathrm{~K}\right][28]$

$X_{c}=$ level of cold water in the storage tank [Normalized with the height of storage tank]

$C_{b}=C_{w} m_{b}$ Thermal capacitance of boiler $[\mathrm{J} / \mathrm{K}]$

$C_{w}=$ specific heat capacity of water $[4180 \mathrm{~J} / \mathrm{kgK}]$

$m_{b}=$ mass of water in storage tank $[\mathrm{kg}]$

$T_{\text {hot }}=$ temperature of the hot water in the storage tank $[\mathrm{K}]$

$T_{a}=$ ambient temperature $[\mathrm{K}]$

$T_{a}=15^{\circ} \mathrm{C}$ is considered, and the surface area of storage tank is calculated considering ratio of height to diameter as 2.5 .

When the HP is turned on and there is an exchange of heat between the condenser and the storage tank, the thermocline layer gets disturbed by water turbulence and mixing of water inside the storage tank takes place, which gives an average temperature $\left(T_{a v g}\right)$ of water inside the storage tank as per Equation (4) [11]. During this period $T_{\text {hot }}=T_{\text {avg }}$.

$$
\frac{d T_{\text {hot }}}{d t}=\frac{1}{C_{b}}\left[\dot{Q}_{\text {heat }}-\dot{Q}_{\text {demand }}-U A\left(T_{\text {hot }}-T_{a}\right)\right]
$$

Here,

$\dot{Q}_{\text {demand }}=$ heat demand transfer rate due to flow of water (Thermal Demand) [J/s]

$\dot{Q}_{\text {heat }}=$ heat flow rate of heating element $[\mathrm{J} / \mathrm{s}]$

\section{LV Residential Grid Network}

To maintain grid voltage within its operating limit $( \pm 10 \%)$ in the LV distribution network, when integrated with HPs, good knowledge of voltage profile is necessary. It not only helps to define the control parameters for HP and storage but also provide the environment to evaluate the performance of the proposed controller. A $10 / 0.4 \mathrm{kV} \mathrm{LV}$ transformer substation with 6 feeders and 164 individual households located at Northern Jutland in Denmark is considered and is shown in Figure 3. The detailed grid network has been discussed in [29]. It is a real LV residential grid in North Jutland in Denmark, all the relevant electric grid data were supplied by the distribution grid company that owns the network. Thermal and electrical load profile parameters are discussed in detail in [12] and their daily demand are illustrated in Figure 4a,b, respectively. HPs are connected to each individual house. Steady-state power system analysis is performed using the DigSILENT Power Factory simulation tool to investigate the performance of the proposed controller. Table 1 summarizes the LV grid network. 


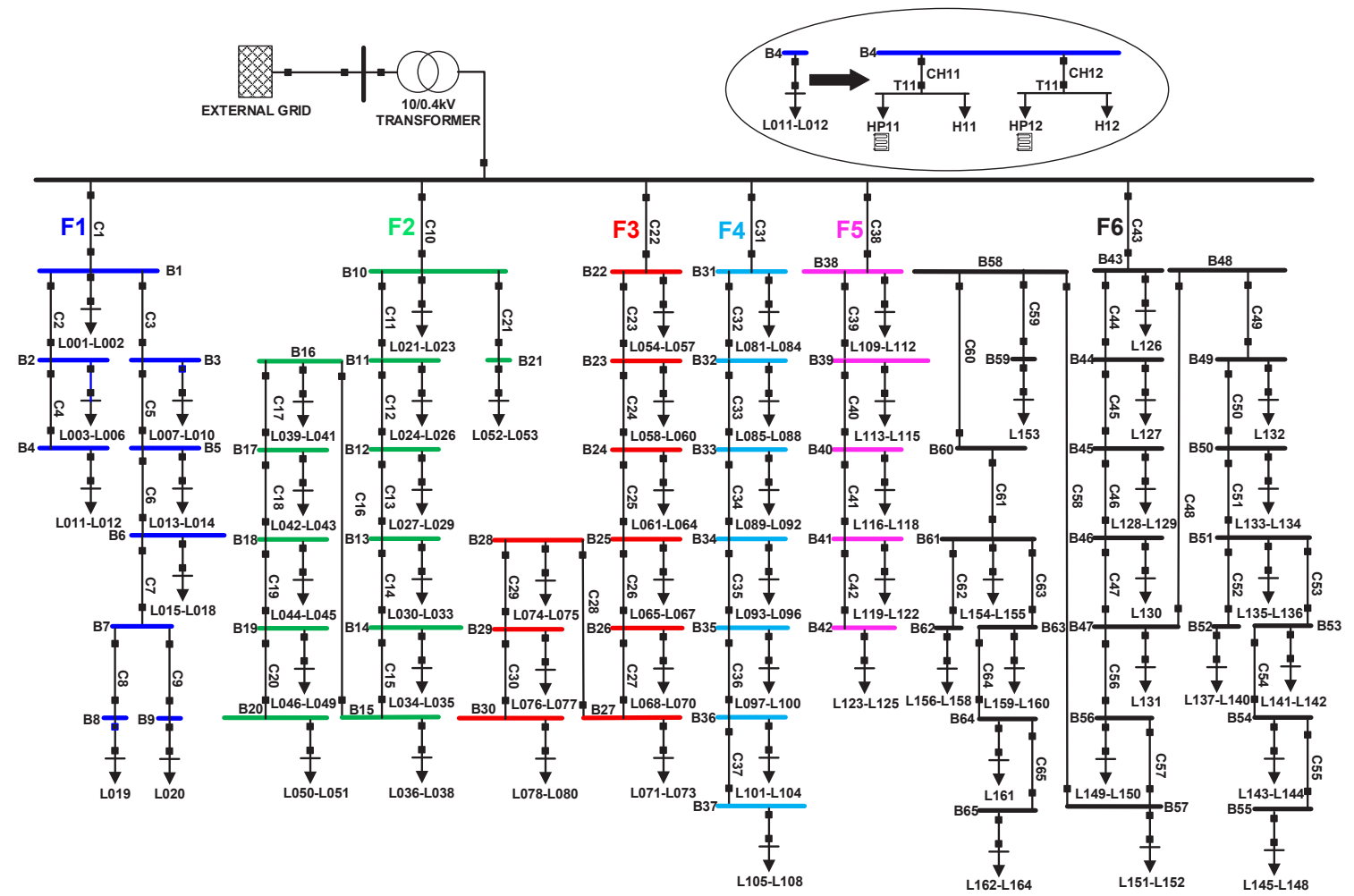

Figure 3. LV Residential Grid Network.
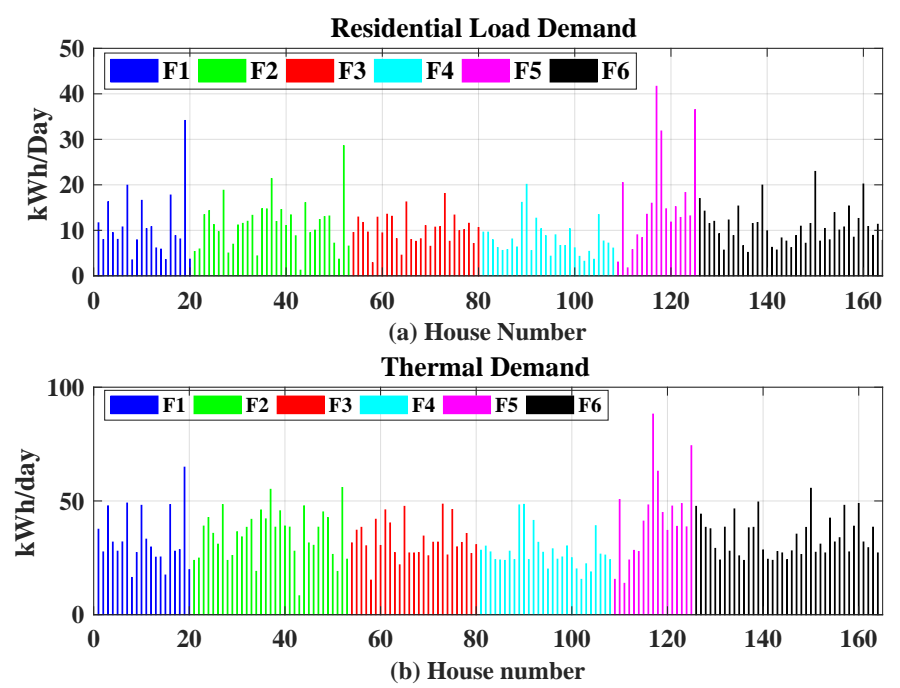

Figure 4. (a) Residential electricity demand (Without HP); (b) Thermal demand for individual houses in their respective feeder.

Table 1. Grid Specifications.

\begin{tabular}{cccccccc}
\hline Transformer Specification & \multicolumn{6}{c}{$\begin{array}{c}\text { 630 kVA, 10/0.4 kV Dyn5, Uk = 4.66\% } \\
\text { Copper Loss }=\mathbf{6 . 5}\end{array}$} \\
\hline NW, Iron Loss = 1.5 kW \\
\hline number of feeders \\
\hline Feeder representation and color & F1 & F2 & F3 & F4 & F5 & F6 \\
\hline Total HH Load in respective feeder (kWh/day) & 226 & 376 & 277 & 223 & 278 & 421 \\
\hline Number of houses in respective feeder & 20 & 33 & 27 & 28 & 17 & 39 \\
\hline
\end{tabular}


Figure $5 \mathrm{a}, \mathrm{b}$ shows the minimum terminal voltages of all feeders with only residential loads (i.e., without any HPs connected). It is clearly seen that feeder F3 and F4 is the strongest feeder of all where minimum voltage attained by terminal T19 and T99 is 0.98 pu, followed by F2-T47 (Feeder 2, terminal 47). Terminals T19, T125, and T162 attain the minimum voltage of 0.95 pu during peak hour in feeders F1, F5, and F6, respectively. F6 is heavily loaded with $421 \mathrm{kWh} /$ day and 39 houses.

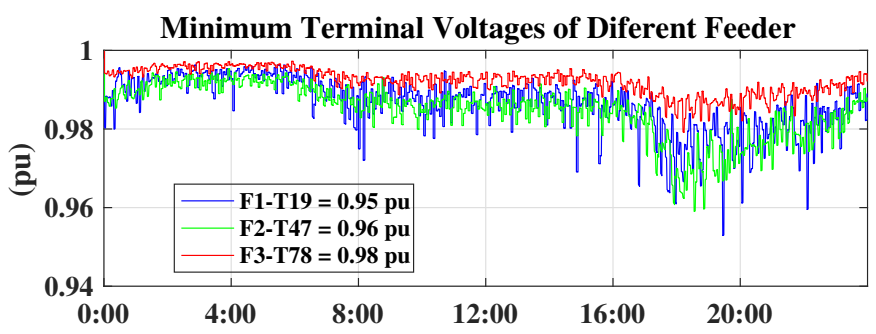

(a) Time

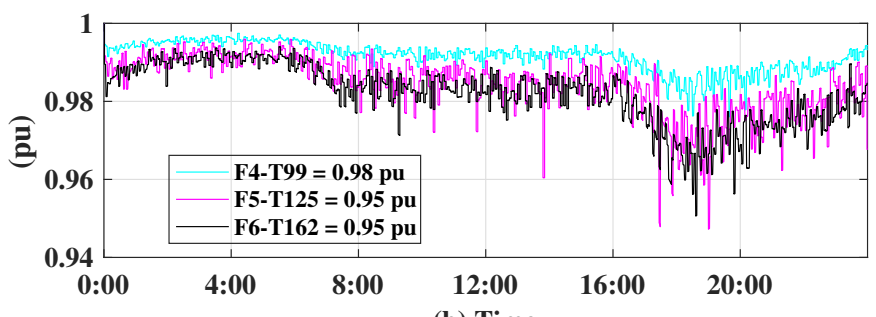

(b) Time

Figure 5. Terminal voltage with the maximum voltage drop of different feeder (a) Terminals in feeder F1, F2, and F3 (b) Terminals in feeder F4, F5, and F6.

\section{Control of HP}

The complete system structure is illustrated in Figure 6. The proposed strategy of individual control unit (as discussed later in this section with Figure 7) integrated with HP allows proper coordination of HPs in the respective feeder to operate within the grid voltage limit, satisfying thermal demand, without the need for centralized communication for the operational schedule of HPs. This is possible with the local information such as status information from the HP-storage ( $T_{\text {hot }}$-Temperature of hot water, $X_{c}$-the level of cold water in the storage tank), and information from the grid ( $V_{t}$-terminal voltage at the point of coupling of HP). This information, along with on/off delay parameters for operation of HP based on the terminal voltage and thermal storage status, is the key control strategy. Hereby, HPs with storages have the potential to contribute as a flexible controllable load to support grid performance (grid voltage, line loading, and transformer capacities), by shifting its operating time. The proposed controller technique is also able to shift the flexibility request among the consumers in the same feeder based on their storage and grid status.

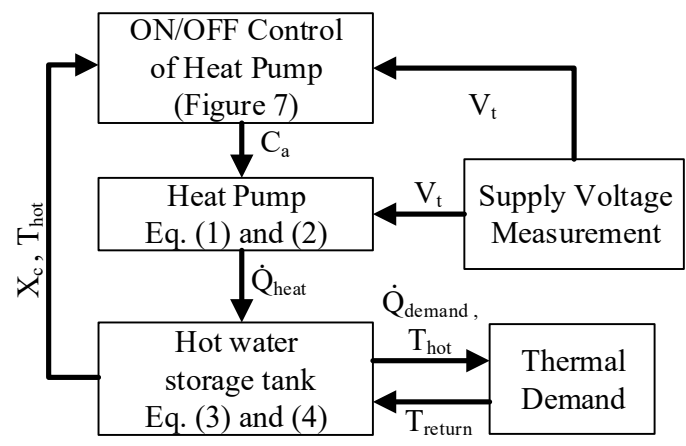

Figure 6. Block diagram of complete system structure. 


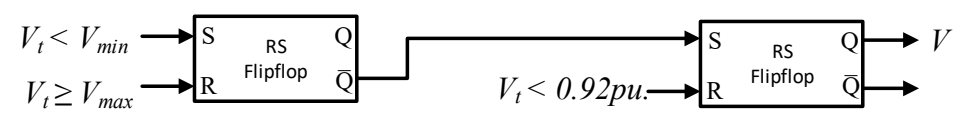

(a)

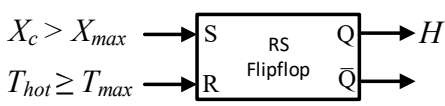

(b)

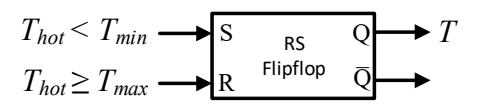

(c)

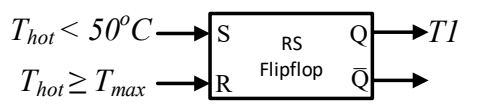

(d)
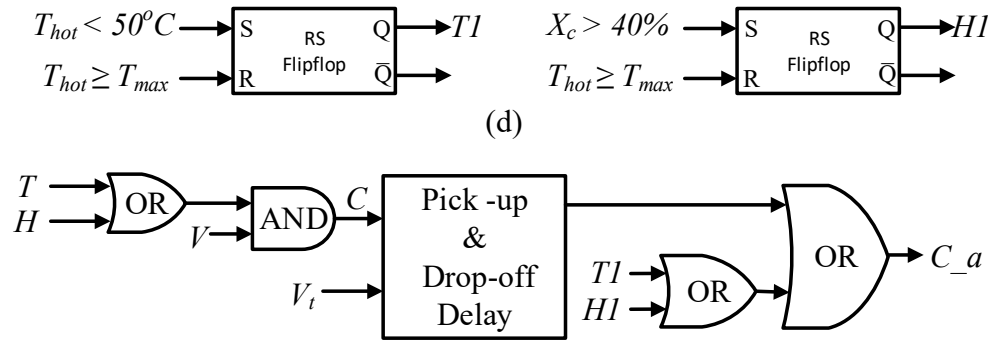

(e)

Figure 7. Schematic Control of HP (a) voltage controller (b) Level Controller (c) temperature Controller (d) Critical Controller (e) Delay Controller along with signal for operation of $\operatorname{HP}\left(C_{a}\right)$.

To determine the control limit to maintain minimum and maximum working temperature of hot water inside the thermal storage tank, it is necessary to know the purpose of thermal demand as well as working limits of commercially available products for the heat exchanger to fulfill user demand. Domestic use of hot water generally includes hot water for the kitchen and bathroom sinks, tubs, and other appliances. It requires an instantaneous water heater with a heat exchanger to ensure that hot water is produced immediately when tapping starts. There are products commercially available that operates with low district heating supply temperature in the range $50-70{ }^{\circ} \mathrm{C}$ with return temperature between $13-18^{\circ} \mathrm{C}$. On the other hand, space heating uses hot water with various techniques such as a radiator or floor heating with a thermostat to control room temperature between $8-28^{\circ} \mathrm{C}$. Thus, in this work the return temperature $\left(T_{\text {return }}\right)$ of hot water to the system is selected to be $30{ }^{\circ} \mathrm{C}$ considering that the thermal demand used for both space heating and domestic uses and is supplied by the same source.

The overall control structure of the HP consists of five different control strategies to ensure proper flexibility in the operation of the HP maintaining grid voltage above its lower operating limit of $-10 \%$ as well as fulfilling consumer demand. The five control strategies are performed using a level controller, temperature controller, voltage controller, critical controller, and a delay controller.

The voltage controller supports to maintains the terminal voltage $\left(V_{t}\right)$, at the point of coupling of the HP to the electrical network, within the lower operating voltage of $-10 \%$. HPs in off state at the terminals where $V_{t}<0.94 \mathrm{pu}$ are not allowed to operate until $V_{t} \geq 0.97 \mathrm{pu}$ to avoid hunting effect and is realized using RS-flipflop logic (without considering its inherent time delays) as shown in Figure 7a. However, HPs which are in on state continues to operate until $V_{t} \geq 0.92 \mathrm{pu}$. This set-up allows the smooth operation of the HPs which are in on state and prevents the operation of HPs that are in off state, during the period when $0.92 \leq V_{t}<0.94$.

The level controller operates to maintains the level of cold water inside the thermal storage tank $\left(X_{c}\right)$ below a minimum level $\left(X_{\min }=25 \%\right)$ so that the temperature of hot water $\left(T_{\text {hot }}\right)$ in the storage tank is maintained between $60-70{ }^{\circ} \mathrm{C}$ in the storage tank. The level controller sends operating signal $(H)$, to operate the HP, when $X_{\mathcal{c}} \geq X_{\min }$ until $T_{\text {hot }} \geq T_{\max }\left(T_{\max }\right.$-maximum allowable temperature in storage tank). This hysteresis in level control is realized using the RS-flipflop logic as shown in Figure $7 \mathrm{~b}$.

The temperature controller operates to maintains the temperature of hot water $\left(T_{\text {hot }}\right)$ between 60-70 ${ }^{\circ} \mathrm{C}$ in the storage tank by sending an operating signal $(T)$, to operate the $\mathrm{HP}$, when the minimum temperature $\left(T_{\text {min }}\right)$ inside the storage tank is below $60{ }^{\circ} \mathrm{C}$. This situation arrives when there is no thermal demand for a long time and due to heat loss from the storage tank, the temperature of hot water drops over time. The temperature control is realized using RS-flipflop logic, as seen in Figure 7c, 
to maintain hysteresis in temperature control i.e., temperature control operates when $T_{\text {hot }}<T_{\min }$ until $T_{\text {hot }} \geq T_{\max }$.

The operation of the HP is mainly dominated by the voltage controller until a critical situation arrives, which is defined by the condition $T_{h o t}<50{ }^{\circ} \mathrm{C}$ or $X_{c}>40 \%$. The critical controller operates during these critical conditions of the thermal storage tank to maintain $T_{\text {hot }}$ between $50-70{ }^{\circ} \mathrm{C}$ despite terminal voltage situation until $T_{\text {hot }} \geq 70^{\circ} \mathrm{C}$. This ensures a continuous supply of thermal demand for end-user applications such as space heating or domestic use. Figure $7 \mathrm{~d}$ shows the schematic of a critical controller realized using RS-flipflop logic.

The delay controller determines the delay for the operation of HPs based on $V_{t}$. The delay logic based on $V_{t}$ plays a vital role to allow operation of HPs in the weak feeder to meet the thermal demand. Delays with Lower pick-up and higher drop-off time corresponding to lower terminal voltage $\left(V_{t}\right)$ prioritize the operation of HPs at the lower end of the distribution feeder, where the $V_{t}$ is lower than the ones closer to the feeder terminal. The controller selects its delay value corresponding to $V_{t}$ based on information provided in Table 2. If $V_{t}<0.94 \mathrm{pu}, \mathrm{HPs}$ are not allowed to connect to the grid until storage is in critical conditions as discussed above. Thus, the critical controller has the highest priority followed by the voltage controller. The temperature and level controller has the least priority in control of HP operation as seen from Figure 7d.

Table 2. Pick-Up and Drop-off Time Delays.

\begin{tabular}{ccc}
\hline Condition & Pick-Up Time (s) & Drop-Off Time (s) \\
\hline$V_{t}<0.94 \mathrm{pu}$ & No HP Connected & $\left(0.97-V_{t}\right) \times m+30$ \\
\hline$V_{t} \geq 0.94 \mathrm{pu}$ & $\begin{array}{c}\left(V_{t}-0.94\right) \times m+60 \\
m=3000 \text { for minimum delay of } 30 \mathrm{~s}\end{array}$ \\
$\begin{array}{ccc}\left(0.97-V_{t}\right) \times m+30 \\
V_{t}<0.92 \mathrm{pu} \text { for } t>60 \mathrm{~s}\end{array}$ & 1800 & 0 \\
\hline Critical Condition & & $\mathrm{N} / \mathrm{A}$ \\
$T 1=1$ OR $H 1=1$ & 0 &
\end{tabular}

For the delay controller the minimum pick-up time delay of $60 \mathrm{~s}$, when $V_{t} \geq 0.94$, is selected to avoid the controllers to respond at short duration variations in terminal voltages. The addition $60 \mathrm{~s}$ for every $0.01 \mathrm{pu}$ rise in voltage is selected to have at least two samples based on the step size used in the simulations ( $30 \mathrm{~s}$ ). The pick-up and drop-off time delay for $V_{t} \geq 0.94 \mathrm{pu}$ is illustrated in Figure 8.

In case the $V_{t}$ is lower than $0.92 \mathrm{pu}$ for $60 \mathrm{~s}$ (two samples to avoid transients), the drop-off time is $0 \mathrm{~s}$ and system reconnects only after $30 \mathrm{~min}(1800 \mathrm{~s})$ of time delay. This is to ensure that the grid does not get stressed frequently due to connection and disconnection of HPs.

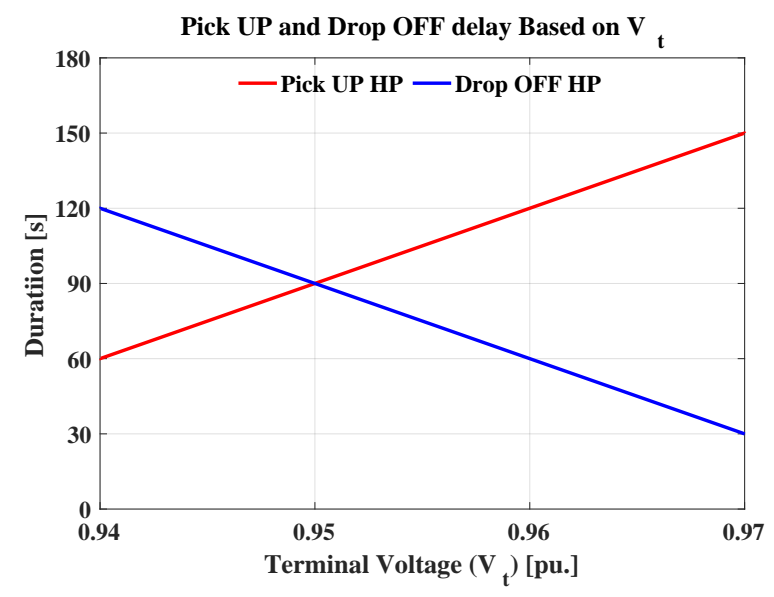

Figure 8. Pick-Up and Drop-Off delay based on $V_{t}$. 
During the event of critical condition, as defined in Figure 7d, HP connects instantaneously without any delay, irrespective of $V_{t}$, until the temperature of hot water in the storage tank reaches its maximum value $T_{\max }$.

Table 3 shows the value of control parameters associated with the control variables shown in Figure 7 for decision-making to operate HPs. Figure 9 shows the validation of the proposed logic for operation of HPs. Around 07:00 hrs, $X_{c}>X_{\min }$ and the logic signal H is set to 1 (Figure 9d). HP delivers heat output $15 \mathrm{~min}$ after the HP is turned on (Figure 9f). Around 13:00 hrs, HP again tries to connect as $X_{c}>X_{\min }$ (Figure 9d). During this time when HP connect to the grid, the grid voltage goes below $0.92 \mathrm{pu}$ for more than $60 \mathrm{~s}$ (Figure 9a). As a consequence, voltage control turns off the HP. Once the HP is disconnected $V_{t}>0.97$ pu but HP gain turns on only after $30 \mathrm{~min}$ (Figure 9f). Again the $V_{t}<0.92 \mathrm{pu}$ and HP turns off. This time $V_{t}$ does not recover its recovery limit of $0.97 \mathrm{pu}$ (Figure 9c) as a result status of the voltage controller is low, meaning unfavorable condition to connect HP at this terminal. Around 19:00 hrs $X_{c}$ is greater than the critical level of cold water in the storage tank $\left(X_{c r i t}\right)$, i.e., $X_{c}>X_{c r i t}$ (Figure 9d) and HP connects instantaneously without any delay and delivers thermal power until storage is fully charged (Figure $9 \mathrm{f}$ ).

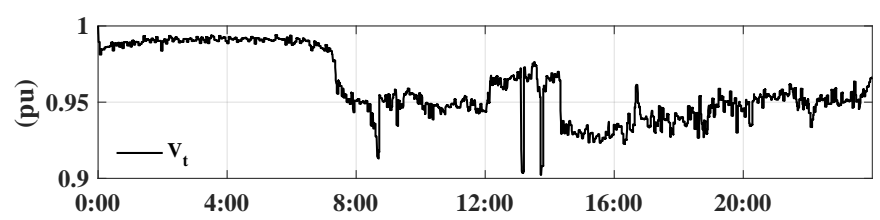

(a)

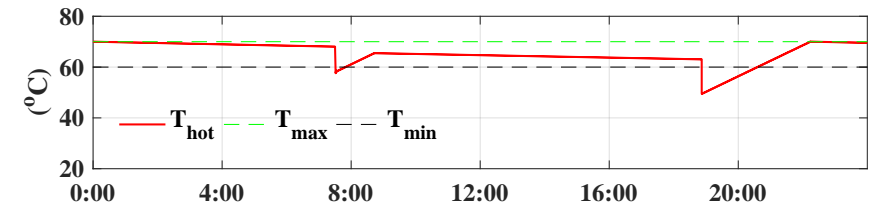

(b)

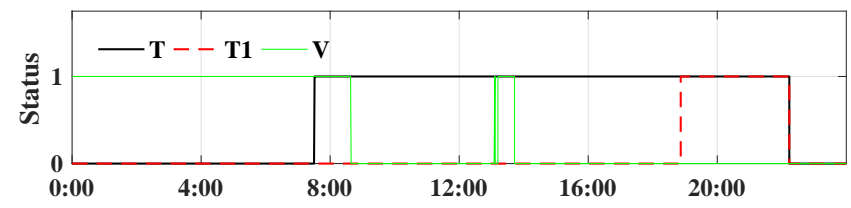

(c)

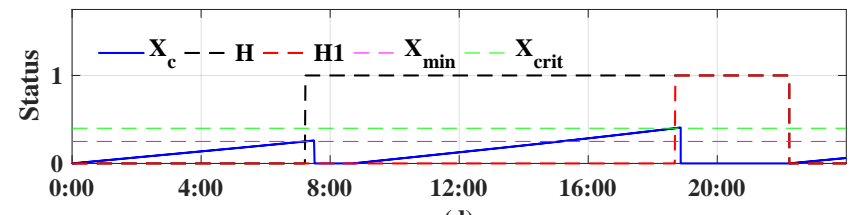

(d)

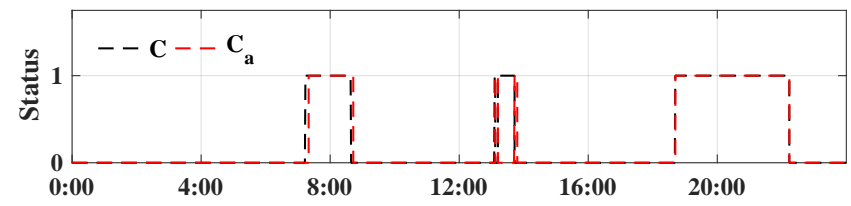

(e)

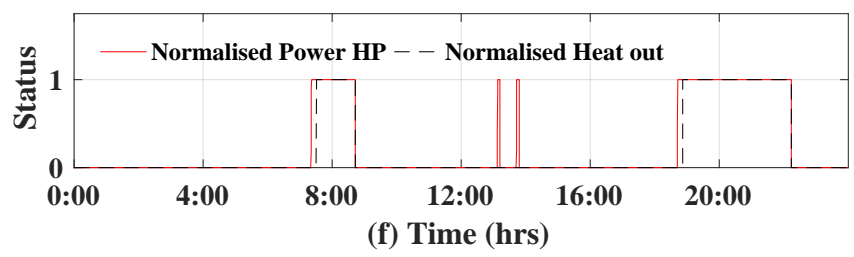

Figure 9. Control Logic (a). terminal voltage $\left(V_{t}\right)$, (b) temperature of hot water inside storage tank, (c-e) control logic status, (f) operation of HP. 
Table 3. Control Parameters.

\begin{tabular}{ccccc}
\hline$T_{\max }\left({ }^{\circ} \mathrm{C}\right)$ & $T_{\min }\left({ }^{\circ} \mathrm{C}\right)$ & $V_{\max }(\mathrm{pu})$ & $V_{\min }(\mathrm{pu})$ & $X_{\min }(\%)$ \\
\hline 70 & 60 & 0.97 & 0.94 & $25 \%$ \\
\hline
\end{tabular}

The decentralized control system based on the control logic with local information presented in this section supports the management of HPs in LV-weak grids and is further discussed in the result and discussion section.

\section{Simulation Environment}

Details on the residential electrical and thermal load demand profile for peak winter is well analyzed in [12]. The houses with higher electricity demand are allocated with higher thermal demand. Table 4 shows the allocation of HP and storage size based on thermal demand to ensure the continuous supply of hot water for at least $8 \mathrm{~h}$ during normal operation when fully charged until $X_{c}>25 \%$. Figure 10 shows the rating of HPs allocated to the individual houses in the proposed LV network.

Table 4. HP and storage tank size allocation.

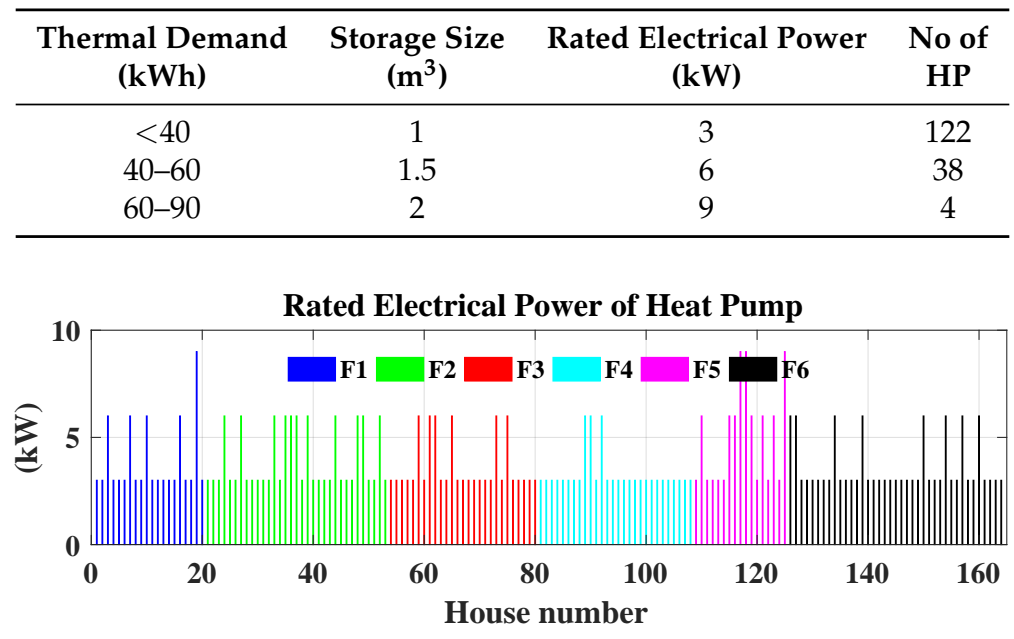

Figure 10. Rated electrical power of HP in individual houses.

Performance of the proposed decentralized controller discussed in Section 4 for integrating HPs in the LV electrical grid is investigated with various case studies. In this work, steady-state power system analysis in the time domain is performed using DigSILENT Power Factory simulation tool. It has the flexibility for developing models and control algorithms of flexible loads and energy storages such as HPs, and further test distribution grid integration and impact studies [30,31]. The model of the heat pump and storage is discussed in Section 2 and the LV residential network is discussed in Section 3.

Various case studies are performed based on different initial conditions for the level of cold water in the storage tank $\left(X_{c}\right)$, the temperature of hot water from the storage $\left(T_{C t r l}\right)$, status of the heating element $\left(C_{a}\right)$, and the operating power factor of the HP as shown in Table 5 . In case I, all the storage tanks are fully charged. In case II, all the storage tanks are fully discharged. This situation closely corresponds to the scenario of a power failure due to various causes, such as natural calamities or fault in the power system, for a longer time period. The random situation is selected for case III. The random numbers are generated from MATLAB. Inverter base HPs with inrush current equal to nominal rating, and coefficient of performance (COP) of 3 for winter condition are considered. Since inverter-based HPs operates either at leading or lagging power factor as discussed in Section 2, it is interesting to observe their synergy with the electricity network for both conditions. Therefore, case IV is set up with lagging power factor with initial conditions as in the case I. 
Table 5. Case studies with different initial condtions.

\begin{tabular}{ccccc}
\hline Case Study & \multicolumn{1}{c}{ Initial Conditions } & & Power Factor \\
\hline & $\boldsymbol{X}_{\boldsymbol{c}}$ & $\boldsymbol{T}_{\text {hot }}$ & $\boldsymbol{C}_{\boldsymbol{a}}$ & $\mathbf{( p f )}$ \\
\hline Case I & 0 & $70^{\circ} \mathrm{C}$ & 0 & 0.95 leading \\
\hline Case II & 1 & $30^{\circ} \mathrm{C}$ & 0 & 0.95 leading \\
\hline Case III & $\begin{array}{c}\text { random } \\
\text { between }(0-1)\end{array}$ & $\begin{array}{c}\text { random } \\
\text { between }\left(30^{\circ} \mathrm{C}-70^{\circ} \mathrm{C}\right)\end{array}$ & $\begin{array}{c}\text { random } \\
0 \text { or } 1\end{array}$ & 0.95 leading \\
\hline Case IV & 0 & $70^{\circ} \mathrm{C}$ & 0 & 0.95 lagging \\
\hline
\end{tabular}

\section{Results and Analysis}

Figures 11 and 12 shows the detailed evaluation and comparison of controller performance with respect to transformer loading, line loading, maximum voltage drop, and performance of the hot water storage tank for the case with leading power factor of HP (case I, II, and III) as mentioned in Table 5. Sub-figures in column 1, 2, and 3 are for case I, II, and III, respectively. The summary of results for day 1,2 , and 3 are tabulated in Tables 6 and 7, whereas figures for day 2 are not presented here. Minimum terminal voltages at the different feeders for all case studies are summarized in Table 7.
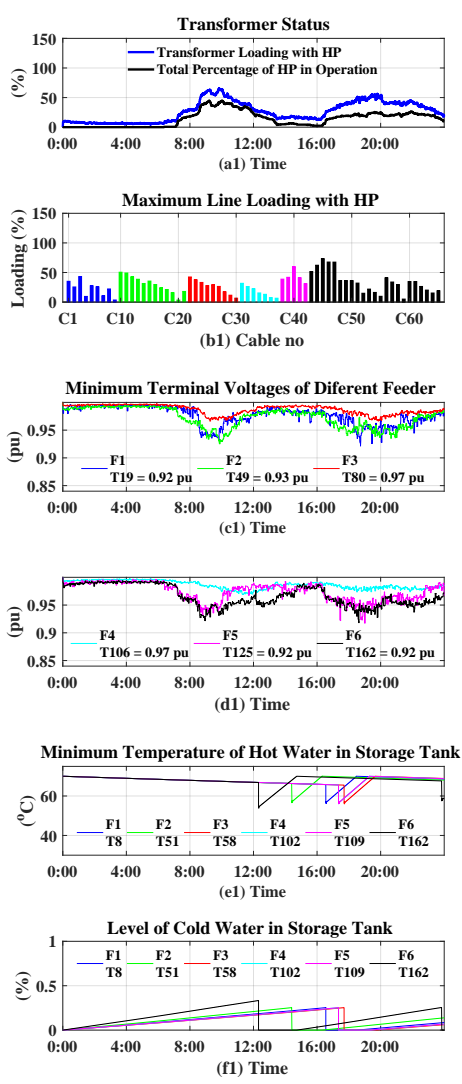

Case I
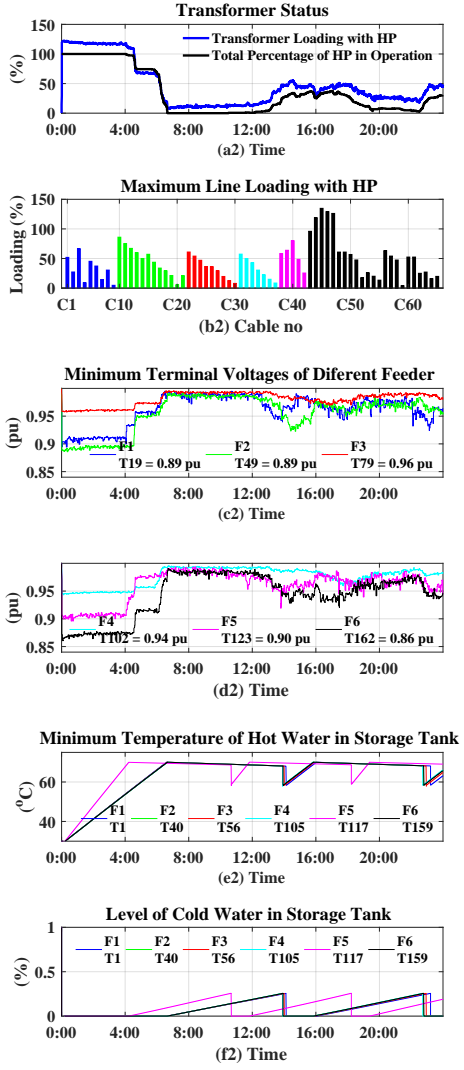

Case II
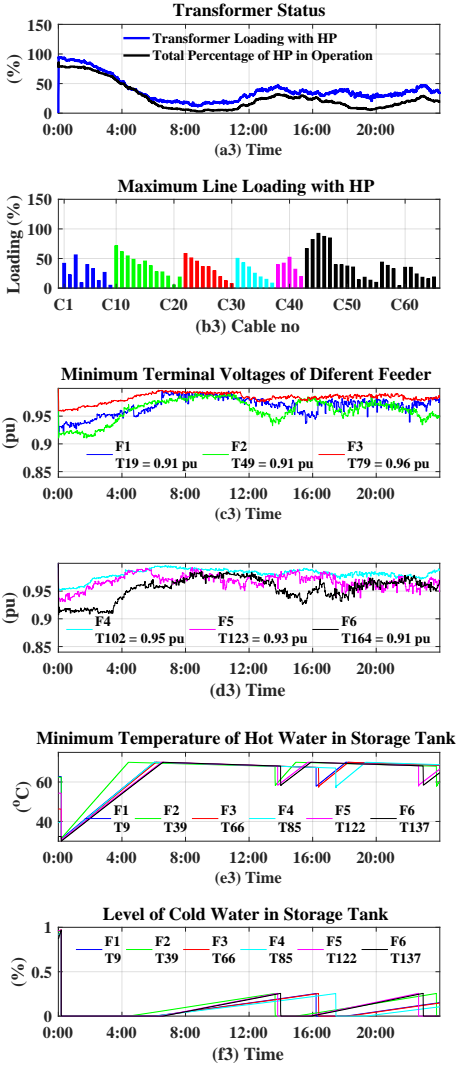

Case III

Figure 11. For day 1: sub-figures in column I, II, and III are for the case I, II, and III, respectively. (a) transformer loading and total percentage of $\mathrm{HP}$ in operation; (b) maximum line loading; (c) minimum voltage attained in terminals of feeder F1, F2 and F3; (d) minimum voltage attained in terminals of feeder F4, F5 and F6; (e,f) minimum attained supply temperature and associated level of cold water in storage tank respectively, in different feeders 

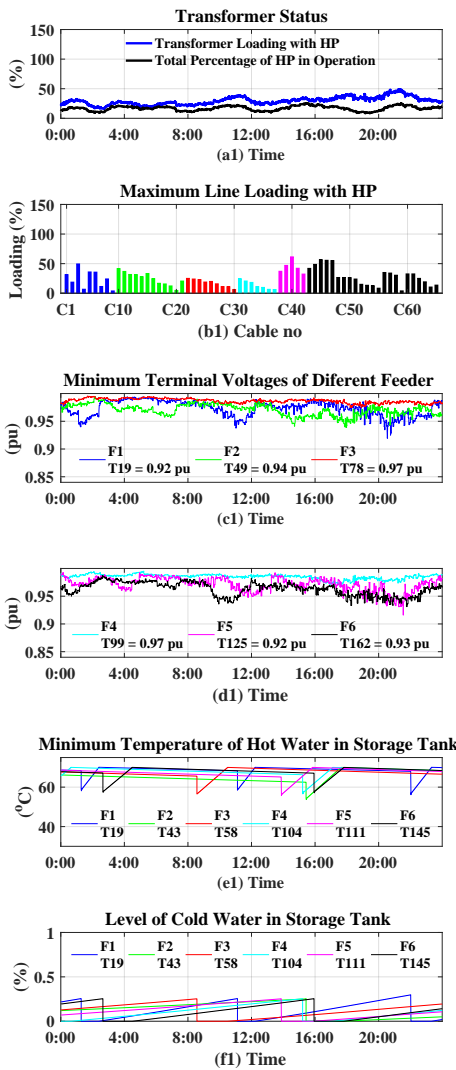

Case I
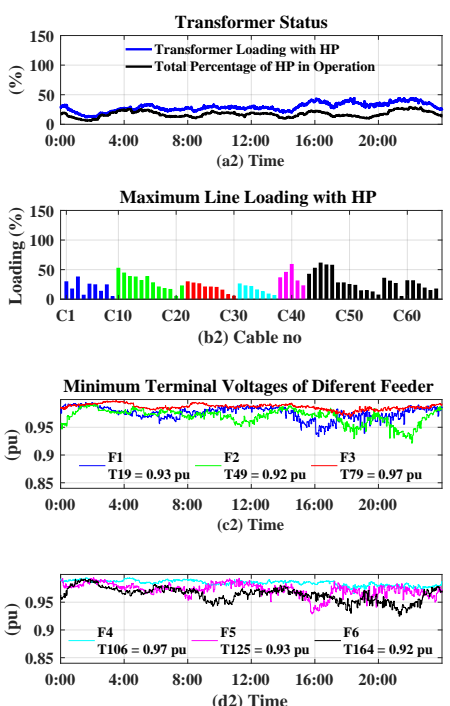

(d2) Time
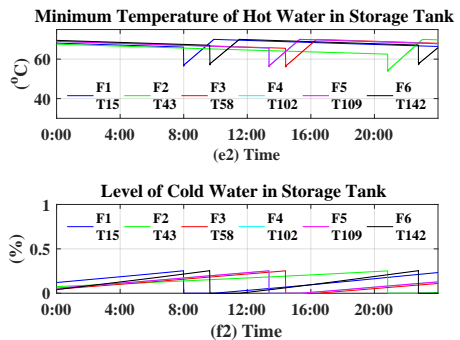

Case II
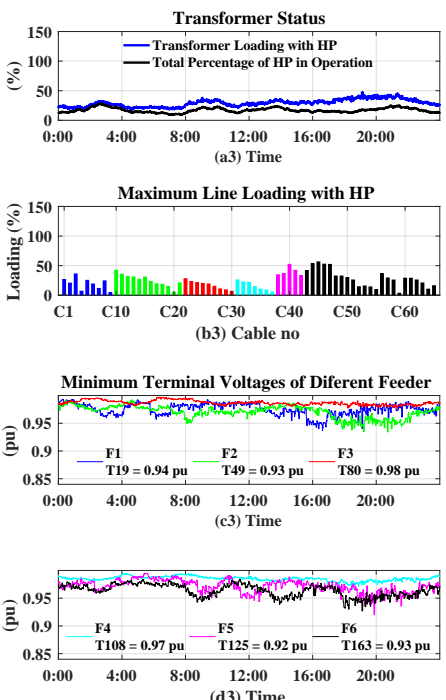

Minimum Temperature of Hot Water in Storage Tank
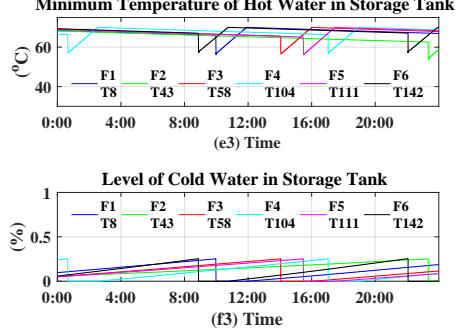

Case III

Figure 12. For day 3: sub-figures in column I, II, and III are for the case I, II, and III, respectively. (a) transformer loading and total percentage of HP in operation; (b) maximum line loading; (c) minimum voltage attained in terminals of feeder F1, F2 and F3; (d) minimum voltage attained in terminals of feeder F4, F5 and F6; (e,f): minimum attained supply temperature and associated level of cold water in storage tank respectively, in different feeders

\subsection{Day 1 Analysis}

Figure 11a shows the transformer loading, and total percentage of HPs operated during the $24 \mathrm{~h}$ period starting from midnight. Figure $11 \mathrm{~b}$ shows the maximum cable loading attained. Figure $11 \mathrm{c}$ illustrates minimum terminal voltages attained in feeder F1, F2, F3 and Figure 11d for F4, F5, F6. The corresponding terminal number with minimum voltage in respective feeders are presented in legend. In order to verify that all the thermal demand are fulfilled without any interruption, the temperature profile of hot water and the corresponding level of cold water in a storage tank, which attains maximum temperature drop in each feeder is shown in Figure 11e,f respectively. The associated terminal with the maximum temperature drop in each feeder is illustrated as a legend. The feeder with a maximum voltage drop is farther from the feeder terminal (Figure 11c,d) whereas, the maximum temperature drop is closer to the feeder terminal (Figure 11e). This suggests that the thermal unit at the far end of the feeder has higher priority to operate, based on the delay setting to turn on and off (as detailed in Table 2) compared to ones closer to the feeder terminal. Similar observations and graphs are presented for Day 3 in Figure 12.

Day 1 analysis as seen in Table 6 clearly shows that for case II (where the storage tank is fully discharged), all HPs operates together, and the transformer is overloaded $22 \%$ more than its rated capacity. Also, the maximum line loading is $135 \%$ for cable C45 Feeder F6 and a few others are heavily loaded (Figure 11(b2)). However, the line loading for all other feeders except F6 can sustain 100\% penetration of HPs in operating condition. On the other hand, cable C45 in feeder F6 along with a few 
other cables are also overloaded for case III (Figure 11(b3)), where the transformer is loaded up to $95 \%$ of its rated capacity (Figure 11(a3)). The maximum level of cold water in a storage tank and the minimum temperature of hot water for case II and III represents the initial condition. However, for case I, the temperature can drop down to $54^{\circ} \mathrm{C}$ for thermal unit connected at terminal T162 of feeder F6 (Figure 11(e1)). The minimum temperature is attained due to the mixing of hot and cold water in the storage tank due to heat exchange during operation of HP as discussed in Section 2. Table 7 indicates that the controller limits the terminal voltages to go below $0.92 \mathrm{pu}$ for case I. However, for case II, there are many HPs storage unit with the level of cold water or temperature of hot water below the critical level as an initial condition. During such a condition the controllers are not effective because of their LV ride through property during the critical stage of the storage tank. However, in the long run, this problem is solved by the controllers which manage to flexibly operate the HPs and storage as seen in day 2 and day 3 analysis.

Table 6. Summary of case studies.

\begin{tabular}{lccccc}
\hline & $\begin{array}{c}\boldsymbol{X}_{\text {mer }} \\
\text { Loading } \\
\text { Max (\%) }\end{array}$ & $\begin{array}{c}\text { HP } \\
\text { Operation } \\
\text { Max (\%) }\end{array}$ & $\begin{array}{c}\text { Line } \\
\text { Loading } \\
\text { Max (\%) }\end{array}$ & $\begin{array}{c}\boldsymbol{X}_{\boldsymbol{c}} \\
\text { Max (\%) }\end{array}$ & $\begin{array}{c}\boldsymbol{T}_{\text {hot }} \\
\text { Min ( }{ }^{\circ} \text { C) }\end{array}$ \\
\hline Case I & 65 & 45 & 73 & 33 & 54 \\
\hline Case II & 122 & 100 & 135 & 100 & 30 \\
\hline Case III & 95 & 86 & 92 & 100 & 30 \\
\hline Case IV & 58 & 41 & 66 & 41 & 48 \\
\hline & \multicolumn{5}{c}{ Simulation I (Day 1) } \\
\hline Case I & 49 & Simulation II (Day 2) & & \\
\hline Case II & 58 & 31 & 70 & 26 & 54 \\
\hline Case III & 53 & 26 & 62 & 26 & 54 \\
\hline Case IV & 49 & 28 & 66 & 35 & 53 \\
\hline & & Simulation III (Day 3) & \\
\hline Case I & 49 & 26 & 61 & 30 & 54 \\
\hline Case II & 44 & 29 & 61 & 26 & 54 \\
\hline Case III & 47 & 28 & 56 & 26 & 54 \\
\hline Case IV & 44 & 28 & 55 & 26 & 53 \\
\hline
\end{tabular}

\subsection{Day 2 and Day 3 Analysis}

Similar observations as in Figure 11 are shown in Figure 12 for day 3. Day 2 and Day 3 analysis shows that the maximum transformer loading $(60 \%)$ and line loading $(69 \%)$ are well within the limit. In the long run, there are no more than $31 \%$ of HPs being operated at any time. Furthermore, the minimum temperature inside the tank is $54^{\circ} \mathrm{C}$ at the time of operation of $\mathrm{HP}$ and the maximum level of cold water in the storage tank is $32 \%$ suggesting that the HP and storage are able to operate flexibly fulfilling the thermal demand simultaneously.

In the long run, despite any initial condition, the HPs coordinates to support peak shaping and line loading (Figure 12a,b), while maintaining the grid voltage (Figure12c,d) as well as thermal demand (Table 6- $T_{\text {hot }}$ ) together. Feeder F3 is the strongest feeder among all with voltage drop down to $0.96 \mathrm{pu}$, and the weakest one is F6. It is observed from Tables 6 and 7, and Figure 12 that the simulation results for all case studies have the similar outcome with respect to line loading, grid voltages, percentage operation of HP, and transformer loading. The grid parameters are well within their operational limit and satisfy the thermal demand simultaneously. 
Table 7. Minimum terminal voltages at different feeder.

\begin{tabular}{|c|c|c|c|c|c|c|}
\hline & $\begin{array}{c}\mathrm{F} 1 \\
(\mathrm{pu})\end{array}$ & $\begin{array}{c}\text { F2 } \\
(\mathrm{pu})\end{array}$ & $\begin{array}{c}\text { F3 } \\
\text { (pu) }\end{array}$ & $\begin{array}{c}\mathrm{F} 4 \\
(\mathrm{pu})\end{array}$ & $\begin{array}{c}\text { F5 } \\
\text { (pu) }\end{array}$ & $\begin{array}{c}\mathrm{F} 6 \\
(\mathrm{pu})\end{array}$ \\
\hline Base Case & 0.95 & 0.96 & 0.98 & 0.98 & 0.95 & 0.95 \\
\hline \multicolumn{7}{|c|}{ Simulation I (Day 1) } \\
\hline Case I & 0.92 & 0.93 & 0.97 & 0.97 & 0.92 & 0.92 \\
\hline Case II & 0.89 & 0.89 & 0.96 & 0.94 & 0.90 & 0.86 \\
\hline Case III & 0.91 & 0.91 & 0.96 & 0.95 & 0.93 & 0.91 \\
\hline Case IV & 0.92 & 0.92 & 0.95 & 0.95 & 0.92 & 0.91 \\
\hline \multicolumn{7}{|c|}{ Simulation II (Day 2) } \\
\hline Case I & 0.94 & 0.93 & 0.97 & 0.96 & 0.92 & 0.93 \\
\hline Case II & 0.92 & 0.94 & 0.97 & 0.96 & 0.92 & 0.92 \\
\hline Case III & 0.93 & 0.93 & 0.97 & 0.97 & 0.92 & 0.93 \\
\hline Case IV & 0.92 & 0.93 & 0.96 & 0.96 & 0.91 & 0.92 \\
\hline \multicolumn{7}{|c|}{ Simulation III (Day 3) } \\
\hline Case I & 0.92 & 0.94 & 0.97 & 0.97 & 0.92 & 0.93 \\
\hline Case II & 0.93 & 0.92 & 0.97 & 0.97 & 0.93 & 0.92 \\
\hline Case III & 0.94 & 0.92 & 0.98 & 0.97 & 0.92 & 0.93 \\
\hline Case IV & 0.92 & 0.92 & 0.97 & 0.96 & 0.92 & 0.92 \\
\hline
\end{tabular}

\subsection{HPs with Lagging Power Factor}

Some inverter-based HPs also operates at lagging 0.95 power factor. Thus, it is interesting to observe how the LV grid behaves for HPs with lagging pf. When the pf of all HPs is set to 0.95 lagging, with the initial condition as in the case I, the result is presented in Figure 13. Column I, II, and III of Figure 13 are for the day I, II, and III. Transformer loading and the total percentage of HP in operation is illustrated in Figure 13a. Compared to the case I (where pf is leading), maximum transformer loading and maximum percentage of HPs in operation are reduced (see Table 6), signifying that with lagging pf, the hosting capacity of LV distribution grid decreases. Figure 13b shows that line loading decreases due to reduction in hosting capacity as compared to case I. Terminal voltages of the terminal attaining minimum voltage in each feeder are shown in Figure 13c,d along with the temperature of hot water and level of cold water in storage tank associated with these terminals are shown in Figure 13e,f respectively. It is interesting to see that the terminal voltage of feeder F6, terminal T162 (Figure 13d), goes below $0.92 \mathrm{pu}$ when the HPs associated with this terminal tries to operate. Thus, the HP in T162 is disconnected to support grid voltage. It again tries to connect after the time delay of $30 \mathrm{~min}$ and disconnects due to poor voltage, until the level of cold water in the storage tank attains critical limit (greater than $40 \%$ ) as seen from Figure 13f. Figure 13e shows that the temperature of hot water in the storage tanks in different feeders at the terminal attaining minimum voltage. It shows that the supply temperature of hot water is well above $50{ }^{\circ} \mathrm{C}$. In the long run, as seen from Figure 13 for day II and day III, HP coordinates to support peak shaping and maintain grid voltage simultaneously. 

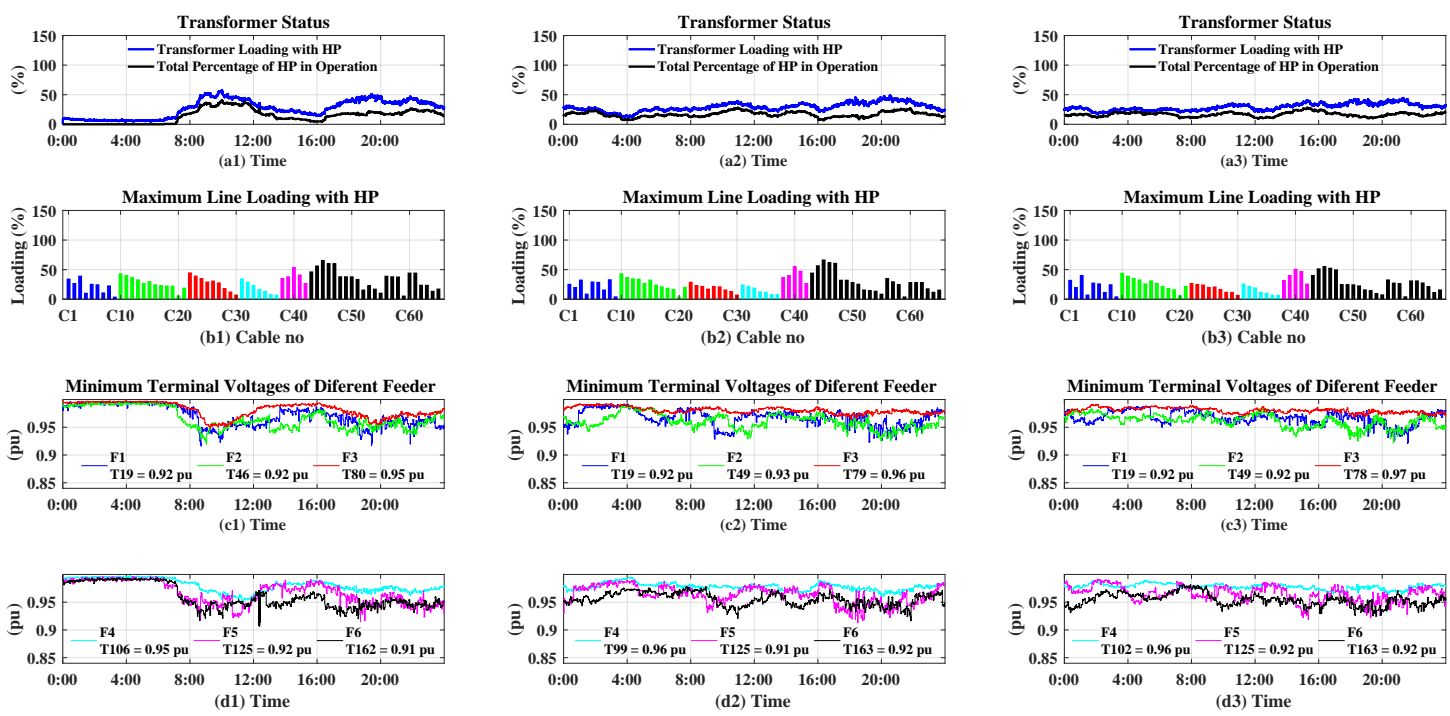

Temperature of Hot Water in Storage Tank at Terminal
With Minimum Voltages in Different Feeders

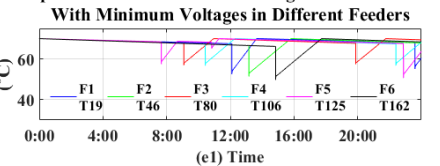

Temperature of Hot Water in Storage Tank at Termina With Minimum Voltages in Different Feeders
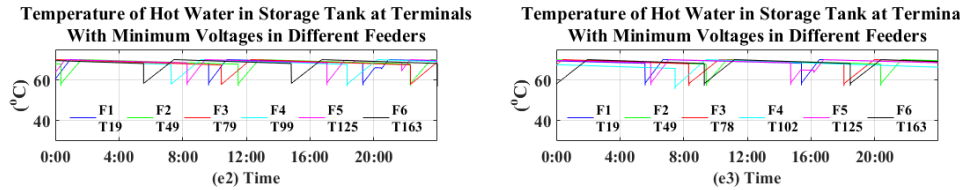

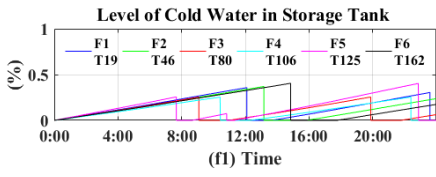

Day I

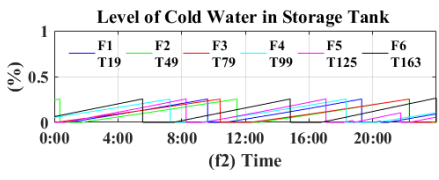

Day II

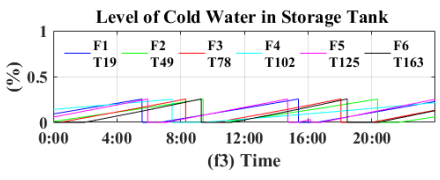

Day III

Figure 13. For Case 4 Lagging pf: sub-figures in column I, II, and III are for the Day I, II, and III, respectively. (a). transformer loading and total percentage of HP in operation; (b) maximum line loading; (c) minimum voltage attained in terminals of feeder F1, F2 and F3; (d) minimum voltage attained in terminals of feeder F4, F5 and F6; (e,f) Temperature of supply hot water from storage and level of cold water respectively

\subsection{Discussion}

The effectiveness of the proposed controller is well explored in this section for strong as well as in weak feeders. The effect of leading and lagging power factor of HPs in grid voltage fluctuation is well observed with the effectiveness of controller performance to set them within the operating limit of terminal voltage between 1-0.9 pu, together with the fulfillment of thermal demand. This enhances application for integrating renewables and synergy with $\mathrm{P} 2 \mathrm{H}$, supporting operation and planning of active grids. More voltage drop is observed with lagging power factor, compared to leading. By controlling its power factor, inverter-based HPs have potential to support grid voltage with many $\mathrm{PV}$ or wind turbines. The set points for the controller (control variables) can be specified for a particular network based on its capacity. If required, the set point of controllers can be changed individually (when there are some changes in the grid infrastructure) and is not needed frequently.

Flexibility is shared among the different HPs in the same feeder based on measurement and controlled variables. The controller fails to operate only when many storage tanks are below the critical level as seen in case II and case III initial conditions. In the long run, it manages to stabilize the system flexibility and satisfying demand simultaneously without any need for communication infrastructure, as a cost-effective solution for flexible load management of heating systems, minimizing grid reinforcements.

Along with the necessity to maintain thermal comfort of users at households, the reliable and stable operation of LV distribution grid are equally important when integrating sizeable loads such as 
HPs. With an increase in renewable energy generation, these HPs and storages are considered to be one of the major technologies that can provide flexibility to the power system providing efficient heating as well as storage of energy. Therefore, for the successful integration and use of HPs in distribution grids, it is important to understand the overall scenario of how the system is affected. Analysis of the distribution grid from the perspective of HP control and its effect on the grid voltage, line loading and transformer loading along with user comfort (as seen from level and temperature of hot water in the storage tank) presents the effectiveness of the proposed controller. The effect of selecting initial condition regarding the status of HP (on/off) and storage (level and temperature of hot water) in the LV grid are thoroughly analyzed based on its effect on grid voltage, and transformer and cable loadings. Same initial condition as in study case I and II introduces operating bottle necks in the LV grid on day one, whereas in long run despite any initial condition, the total percentage of HP in operation at a time is between $25-30 \%$ as seen for the analysis of day 3 analysis in Table 6 . This reflects the distributed operation of HP over time that enables flexible peak shaping of the electricity demand as well as preventing under-voltage (day 3-Table 7) in the far end of the radial feeder. The peak loading of the transformer is just below $50 \%$ (day 3-Table 6) indicating that with proper demand control, more sizeable electrical loads, such as electric vehicles, can also be integrated in the future by adopting such simple and effective local controls. However, considering grid voltage of feeder F6 (Figures 11, 12 and 13c,d) there is a necessity of grid reinforcement in feeder F6 to ensure terminal voltage at the end nodes are within operating thresholds.

The results show that the proposed control architecture of HPs can reduce the need for costly grid reinforcement as well as a separate communication infrastructure for handling of big data, and complex control architecture. Hence, it is beneficial to both the networks/systems and the involved stakeholders. It not only reduces the network impact but also provides flexibility in production, conversion, storage, and end-use through the efficient coordination of the HP operation, helping to lower the electricity consumption at peak times. Synergies among the thermal and electrical systems with the interaction between local and distributed generation units such as wind solar have potential in the future. Thus, the results and findings from the work are in line with the contemporary integrated sustainable energy system concept. This work can be further carried out with economical aspects, scheduling and aggregation services based on forecasting and energy price.

\section{Conclusions}

HPs with storage is a good source of P2H in smart energy systems. Higher COP compared to EBs, and storage tank as energy buffer increases its potential as a flexible load and storage solution in future smart grid systems. This paper has analyzed the flexibility of individual HPs in every household, particular to the input voltage in the LV distribution network. The use of a simple local controller can satisfy the consumer demand while coordinating among the various HPs in the same electrical feeder, minimizing transformer loading, line loading, and voltage drop in the long run. Different scenarios based on leading and lagging power factor of HPs, and initial operating condition of HP and storages are demonstrated in a LV network with 164 households. The potential cost-effective solution towards P2H synergy in smart energy system has been presented with the use of the local controller for the individual HP.

Author Contributions: R.S. developed the methodology, corresponding models, and wrote the paper. B.B.-J. and J.R.P. supervised the work and reviewed the paper.

Funding: This work is supported by the Innovation fund Denmark through the DiCYPS project.

Acknowledgments: The data for the analysis has been provided by Aalborg Energi Holding A/S and Aalborg University, Denmark, as per the agreement between project partners for research.

Conflicts of Interest: The authors declare no conflict of interest. 


\section{References}

1. Connolly, D.; Lund, H.; Mathiesen, B.; Werner, S.; Möller, B.; Persson, U.; Boermans, T.; Trier, D.; Østergaard, P.; Nielsen, S. Heat Roadmap Europe: Combining district heating with heat savings to decarbonise the EU energy system. Energy Policy 2014, 65, 475-489. [CrossRef]

2. Ommen, T.; Markussen, W.B.; Elmegaard, B. Lowering district heating temperatures-Impact to system performance in current and future Danish energy scenarios. Energy 2016, 94, 273-291. [CrossRef]

3. Lund, R.; Østergaard, D.; Yang, X.; Mathiesen, B. Comparison of Low-temperature District Heating Concepts in a Long-Term Energy System Perspective. Int. J. Sustain. Energy Plan. Manag. 2017, 12, 5-18.

4. Neirotti, F.; Noussan, M.; Riverso, S.; Manganini, G. Analysis of Different Strategies for Lowering the Operation Temperature in Existing District Heating Networks. Energies 2019, 12. [CrossRef]

5. Swing Gustafsson, M.; Myhren, J.A.; Dotzauer, E. Life Cycle Cost of Heat Supply to Areas with Detached Houses-A Comparison of District Heating and Heat Pumps from an Energy System Perspective. Energies 2018, 11. [CrossRef]

6. Averfalk, H.; Ingvarsson, P.; Persson, U.; Gong, M.; Werner, S. Large heat pumps in Swedish district heating systems. Renew. Sustain. Energy Rev. 2017, 79, 1275-1284. [CrossRef]

7. Lund, H.; Möller, B.; Mathiesen, B.; Dyrelund, A. The role of district heating in future renewable energy systems. Energy 2010, 35, 1381-1390. [CrossRef]

8. Dongellini, M.; Abbenante, M.; Morini, G. A strategy for the optimal control logic of heat pump systems: impact on the energy consumptions of a residential building. In Proceedings of the 12th IEA Heat Pump Conference 2017, Rotterdam, The Netherlands, 15-18 May 2017.

9. Madani, H.; Claesson, J.; Lundqvist, P. A descriptive and comparative analysis of three common control techniques for an on/off controlled Ground Source Heat Pump (GSHP) system. Energy Build. 2013, 65, 1-9. [CrossRef]

10. Merkert, L.; Haime, A.A.; Hohmann, S. Optimal Scheduling of Combined Heat and Power Generation Units Using the Thermal Inertia of the Connected District Heating Grid as Energy Storage. Energies 2019, 12. [CrossRef]

11. Sinha, R.; Jensen, B.B.; Pillai, J.R.; Moller-Jensen, B. Unleashing Flexibility from Electric Boilers and Heat Pumps in Danish Residential Distribution Network. In Proceedings of the CIGRE 2018, Paris, France, 26-31 August 2018.

12. Sinha, R.; Jensen, B.B.; Radhakrishnan Pillai, J. Impact Assessment of Electric Boilers in Low Voltage Distribution Network. In Proceedings of the 2018 IEEE Power Energy Society General Meeting (PESGM), Portland, OR, USA, 5-9 August 2018; pp. 1-5. [CrossRef]

13. Akmal, M.; Fox, B.; Morrow, D.J.; Littler, T. Impact of high penetration of heat pumps on low voltage distribution networks. In Proceedings of the 2011 IEEE Trondheim PowerTech, Trondheim, Norway, 19-23 June 2011; pp. 1-7. [CrossRef]

14. Molitor, C.; Marin, M.; Hernández, L.; Monti, A. Decentralized coordination of the operation of residential heating units. In Proceedings of the IEEE PES ISGT Europe 2013, Copenhagen, Denmark, 6-9 October 2013; pp. 1-5. [CrossRef]

15. Pudjianto, D.; Djapic, P.; Aunedi, M.; Gan, C.K.; Strbac, G.; Huang, S.; Infield, D. Smart control for minimizing distribution network reinforcement cost due to electrification. Energy Policy 2013, 52, 76-84. [CrossRef]

16. Esterl, T.; Leimgruber, L.; Ferhatbegovic, T.; Zottl, A.; Krottenthaler, M.; Weiss, B. Aggregating the flexibility of heat pumps and thermal storage systems in Austria. In Proceedings of the 2016 5th International Conference on Smart Cities and Green ICT Systems (SMARTGREENS), Rome, Italy, 23-25 April, 2016.

17. Hong, J.; Kelly, N.J.; Richardson, I.; Thomson, M. Assessing heat pumps as flexible load. Proc. Inst. Mech. Eng. Part J. Power Energy 2013, 227, 30-42. [CrossRef]

18. Pedersen, T.S.; Nielsen, K.M.; Andersen, P. Maximizing storage flexibility in an aggregated heat pump portfolio. In Proceedings of the 2014 IEEE Conference on Control Applications (CCA), Nice, France, 8-10 October 2014; pp. 286-291. [CrossRef]

19. Zhang, L.; Chapman, N.; Good, N.; Mancarella, P. Exploiting electric heat pump flexibility for renewable generation matching. In Proceedings of the 2017 IEEE Manchester PowerTech, Manchester, UK, 18-22 June 2017; pp. 1-6. [CrossRef] 
20. Bhattarai, B.P.; Kouzelis, K.; Mendaza, I.D.D.C.; Bak-Jensen, B.; Pillai, J.R.; Myers, K.S. Smart Grid Constraint Violation Management for Balancing and Regulating Purposes. IEEE Trans. Ind. Inform. 2017, 13, 2864-2875. [CrossRef]

21. Jennings, N.R.; Bussmann, S. Agent-based control systems: Why are they suited to engineering complex systems? IEEE Control Syst. Mag. 2003, 23, 61-73. [CrossRef]

22. Baillieul, J.; Antsaklis, P.J. Control and Communication Challenges in Networked Real-Time Systems. Proc. IEEE 2007, 95, 9-28. [CrossRef]

23. Masuta, T.; Yokoyama, A.; Tada, Y. Modeling of a number of Heat Pump Water Heaters as control equipment for load frequency control in power systems. In Proceedings of the 2011 IEEE Trondheim PowerTech, Trondheim, Norway, 19-23 June 2011; pp. 1-7. [CrossRef]

24. Heffernan, W.J.B.; Watson, N.R.; Buehler, R.; Watson, J.D. Harmonic Performance of Heat-Pumps. IET J. Eng. 2013, 9, 31-44. [CrossRef]

25. Heffernan, W.J.B.; Watson, N.R.; Watson, J.D. Heat-pump Performance: Voltage dip/sag, Under-Voltage and Over-Voltage. J. Eng. 2014, 2014, 640-657. [CrossRef]

26. Sinha, R.; Jensen, B.B.; Pillai, J.R.; Bojesen, C.; Moller-Jensen, B. Modelling of hot water storage tank for electric grid integration and demand response control. In Proceedings of the 2017 52nd International Universities Power Engineering Conference (UPEC), Crete, Greece, 28-31 August 2017; pp. 1-6. [CrossRef]

27. Han, Y.; Wang, R.; Dai, Y. Thermal stratification within the water tank. Renew. Sustain. Energy Rev. 2009, 13, 1014-1026. [CrossRef]

28. Mawire, A.; Taole, S.H. Heat loss estimation in a small vertical cylindrical stratified oil storage tank. In Proceedings of the 2013 21st Domestic Use of Energy Conference, Cape Town, South Africa, 3-4 April 2013, pp. 1-7.

29. Pillai, J.R.; Thøgersen, P.; Møller, J.; Bak-Jensen, B. Integration of Electric Vehicles in low voltage Danish distribution grids. In Proceedings of the 2012 IEEE Power and Energy Society General Meeting, San Diego, CA, USA, 22-26 July 2012; pp. 1-8. [CrossRef]

30. DigSILENT. Available online: https:/ / www.digsilent.de/en/powerfactory.html (accessed on 2 February 2019).

31. Bjerregaard, P.T.; Szczesny, I.G.; de Cerio Mendaza, I.D.; Pillai, J.R. Intelligent control of flexible loads for improving low voltage grids utilization. In Proceedings of the IEEE PES ISGT Europe 2013, Copenhagen, Denmark, 6-9 October 2013; pp. 1-5. [CrossRef]

(C) 2019 by the authors. Licensee MDPI, Basel, Switzerland. This article is an open access article distributed under the terms and conditions of the Creative Commons Attribution (CC BY) license (http://creativecommons.org/licenses/by/4.0/). 